\title{
Briciclib Sodium
}

National Cancer Institute

\section{Source}

National Cancer Institute. Briciclib Sodium. NCI Thesaurus. Code C90541.

A benzyl styryl sulfone analog, and a disodium phosphate ester prodrug of ON 013100 , with potential antineoplastic activity. Upon hydrolysis, briciclib is converted to ON 013100 , which blocks cyclin D mRNA translation and decreases protein expression of cyclin D. This may induce cell cycle arrest and apoptosis in cancer cells overexpressing cyclin D and eventually decrease tumor cell proliferation. This agent may exhibit synergistic antitumor activity in combination with other chemotherapeutic agents. Cyclin D, a member of the cyclin family of cell cycle regulators, plays a key role in cell cycle division and is often overexpressed in a variety of hematologic and solid tumors and is correlated with poor prognosis. 